\title{
Application of Electrolytic Plasma Process in Surface Improvement of Metals: A Review
}

\author{
Vitthal R. Jumbad ${ }^{1}$, Arvind Chel ${ }^{2}$ (D), Updesh Verma ${ }^{3}$, Geetanjali Kaushik ${ }^{4, *(D)}$ \\ 1 Research Scholar, MGM's JNEC Research Center, Aurangabad-431003, Maharashtra, India \\ 2 Dept. of Mechanical Engineering, MGM's Jawaharlal Nehru Engineering College, Aurangabad-431003, Maharashtra, \\ India \\ 3 Raman Postdoc Fellow at Princeton Plasma Physics laboratory (PPPL) Princeton University, Princeton, New Jersey- \\ 08544. MKR Government Degree College, Ghaziabad-201003, Uttar Pradesh, India \\ 4 Dept. of Civil Engineering, Hi-Tech Institute of Technology, Waluj- 431136, Maharashtra, India \\ * Correspondence: geetanjaliac@gmail.com;
}

Scopus Author ID 24335102900

Received: 26.05.2020; Revised: 20.06.2020; Accepted: 21.06.2020; Published: 26.06.2020

\begin{abstract}
Electrolytic plasma heat treatment is becoming a popular heat treatment process in the field of surface engineering. In this paper, research data from different research works have been analyzed. The basic mechanism of the electrolytic plasma heat treatment process is discussed along with its scope in the industry. The review is done to extend the research work of this novel process and its scope from the industrial point of view. The study will explore the electrolytic plasma process to target industrial benefits and to attract the researchers for improving the various aspects of the process. Different types of electrolytic plasma treatment have been discussed to show the capabilities of the process for improving surface properties of different metals. It is found that the treatment is less time consuming, economical, eco-friendly, and dynamic as compared to the existing heat treatment processes. Its dynamic ability makes it possible to perform carburizing, nitriding, coating, cleaning, polishing, and hardening operations in the same experimental setup with little modification.
\end{abstract}

Keywords: Plasma Electrolytic Treatment (PET); Electrolytic Plasma Heat Treatment(EPHT).

(C) 2020 by the authors. This article is an open-access article distributed under the terms and conditions of the Creative Commons Attribution (CC BY) license (https://creativecommons.org/licenses/by/4.0/).

\section{Introduction}

Surface improvement of metals is made to increase working life, improve the performance, and giving an aesthetic look to the metallic components. Surface properties of steel, such as wear resistance, hardness, and corrosion resistance, can be improved by surface modification processes that involved hardening, nitriding, carburizing, and nitrocarburizing. Similarly, a protective layer of a particular material can also be introducing on the surface of metals.

In the industry where steel is used in the manufacturing of every component, surface improvement plays a vital role in introducing desired mechanical properties in the steel. Press tool shops, automobile companies, press part manufacturers, aerospace industry, shipbuilding industry, Biomedical equipment manufacturer, weapon manufacturing industry are some of the areas where steel is a common metal, and hence improving the properties of steel by different techniques becomes important. Traditionally only heating and cooling of steel was the most common method of surface treatment that exist as time passed, different surface treatments evolved. Conventional heat treatment consists of heating metal in the furnace and cooling in 
air, water, or oil. There are also other heat treatment processes used to improve surface properties of steel such as nitriding, carburizing, vacuum heat treatment, cryogenic heat treatment, laser heat treatment, ion beam heat treatment, etc. All these processes require highcost setup, time of treatment is more, some processes are not eco-friendly and some are having bulky apparatus. The electrolytic plasma treatment is a novel method to encounter all these disadvantages. It is proving that it can successfully improve desired mechanical properties with much less time about few minutes as compared to traditional heat treatment processes, which require hrs and days. Also, very low-cost equipment is required, and the process is eco-friendly.

The purpose of this review is to study and focus on the various aspects of a novel method of heat treatment known as Plasma Electrolytic treatment for identifying its scope and exploring areas of challenges in it.

It is proved that electrolytic plasma treatment can successfully improve wear resistance and corrosion resistance of steel. Also, a considerable depth of hardness can be achieved in the case of tool steel to increase tool life. Single setup of an experiment can perform a different type of surface treatment such as hardening, nitriding, carbonitriding, plating, polishing, and cleaning. However, though the process is carried out for the different type of steel as well as aluminum, there is no standardized material-wise heat treatment cycle have been established till the date. Also, as the plasma formation is an instantaneous process and occurs within a fraction of seconds, it becomes difficult to stabilize the input process parameters to gain the output parameters as per our need. Due to its present technical challenges, the process is still in the development phase and not commercialized worldwide, like other processes such as cryogenics and vacuum heat treatment. Cathodic electrolytic plasma hardening of cast iron based camshaft has been carried out, and it was observed that the hardness of cast iron based automotive camshaft increased to $60 \mathrm{HRC}$ with $5 \mathrm{~mm}$ depth of hardness [20]. A $20 \mu \mathrm{m}$ thick layer of hardness around $460 \mathrm{HV}$ has achieved by plasma electrolytic nitriding at $850^{\circ} \mathrm{C}$ only for $5 \mathrm{~min}$ in the case of Titanium alloy [23]. The highest microhardness of $950 \mathrm{HV}$ is achieved by Plasma Electrolytic Nitriding, and also surface roughness was reduced from 4.5 to $1.9 \mu \mathrm{m}$ [40].

Anode plasma electrolytic nitro hardening in $15 \mathrm{wt} . \% \mathrm{NH} 4 \mathrm{Cl}$ as an electrolyte has been successfully carried out, and microhardness of about $1060 \mathrm{HV}$ was obtained within $5 \mathrm{~min}$ at a temperature of $750^{\circ} \mathrm{C}$ [49]. Low carbon steel, when treated with plasma electrolytic nitrocarburizing at $850^{\circ} \mathrm{C}$, shown an increase in hardness up to $750 \mathrm{HV}$ with $0.2 \mathrm{~mm}$ depth of hardness. It was proposed that anode plasma electrolytic nitrocarburizing increases wear resistance and decrease surface roughness of low carbon steel [50]. Plasma electrolytic nitriding carried out with plasma electrolytic hardening has achieved a combination of high hardness and wear resistance. The hardness of 56-62 HRC was obtained by plasma electrolytic hardening, and after that, the corrosion resistance was improved by nitriding. Both processes were carried out in the same electrolyte and same setup [51]. Cathodic electrolytic plasma hardening has also been carried out, and it was found that the hardness of cast iron based automotive camshaft increased to 60HRC with $5 \mathrm{~mm}$ depth of hardness [20]. High surface finishing of a 38KH2N2MA Structural alloy steel was achieved by using a combination of Electrolytic Discharge Machining and Plasma Electrolytic Polishing. It was concluded that the surface roughness reduced by a factor of 5 within a $5 \mathrm{~min}$ anodic plasma electrolytic process [52]. A coating thickness of $80 \mu \mathrm{m}$ was successfully achieved by electrolytic plasma oxidation. The specimen used was VT6 titanium alloy and coating formed was of Titanium oxide [53]. Electrolytic plasma hardening of Banding steel has increases microhardness by 2.4 times of 
substrate within $4 \mathrm{~s}$ of heating [55]. The phase composition of electrolytic plasma carbonitrided steel specimen has been studied by Transmission Electron Microscopy, and it was observed that martensite, cementite, and carbonitrides lamellas were successfully formed on the steel surface [56].

The electrolytic plasma process has been studied by the direct current method and pulse current method. It was proved that for surface hardening of AISI 1050 steel, the pulse current method requires less voltage and time as compared to the direct current method [41]. The corrosion resistance of carbonyl iron powder was increased by depositing the $\mathrm{SiO}_{2}$ layer on the carbonyl surface with the help of plasma electrolytic deposition [54]. Corrosion behavior of SS304 also been studied in which ball-milled specimens were first annealed and then treated with Electrolytic Plasma Process. It was found that the corrosion resistance improved significantly [101]. The deposition rate of oxide coating on Magnesium alloy increases when the Electrolytic Plasma Process was used in pulse polarization mode [70]. Sequential coating and polishing are also possible by using the electrolytic plasma process, which makes this process dynamic and multifunctional [84]. Boriding of structural steel and Titanium alloys was done by using the electrolytic plasma process. It was observed that both wear resistance and corrosion resistance improved significantly in the case of structural steel as well as Titanium alloy [87].

The plasma electrolytic Oxidation process has been used for the coating of aluminum alloy, nickel alloy, titanium alloy, carbon fiber, and many more metals. Machining of aluminum alloy coated with ceramic oxide by electrolytic plasma oxidation process also studied, and it is shown that wear resistance property of aluminum alloy increases and abrasive polishing suggested for final machining of such component [94]. Ti alloy used for bio-implant application shows an increase in wear resistance and corrosion resistance after treated with plasma electrolytic oxidation, and also weldability in terms of contact angle also improved [104].

This electrolytic plasma process is an electrolysis process that is carried out at high voltage to create plasma for heating the metal at high temperatures. A combination of plasma and electrolysis has achieved a novel contribution in the field of surface heat treatment technologies, as shown in figure 1.

The process aspects of the technology have been explained as follows:

\subsection{Plasma.}

There are three states of matter solid, liquid, and gases. Nevertheless, there exists a fourth state also, which is beyond the gaseous state, and it is called plasma. If heat is applied to a liquid, it gets vaporized at high temperatures, and liquid state changes to a gaseous state. When this gaseous is further heated, the free electrons separate from particles, and positive ions with free electrons are formed. These free electrons conduct electricity. The plasma formation phase is indicated by a glow discharge for a very short duration of time, and this glow can heat the metal up to $2000^{\circ} \mathrm{C}$ [1]. This heat is utilized for the surface modification of metals.

\subsection{Electrolysis.}

For the surface modification of steel, it may require to deposit carbon or nitrogen particles on the surface of steel with the help of an external agent. This can be done by electrolysis in which electrode is deposited with carbon or nitrogen atoms by supplying high 
voltage across the electrode dipped in a particular electrolyte. This electrolyte plays an important role in conducting electricity. The combination of plasma and electrolysis can be used to carry out a novel method of surface treatment, which is called as Electrolytic Plasma Surface Treatment.

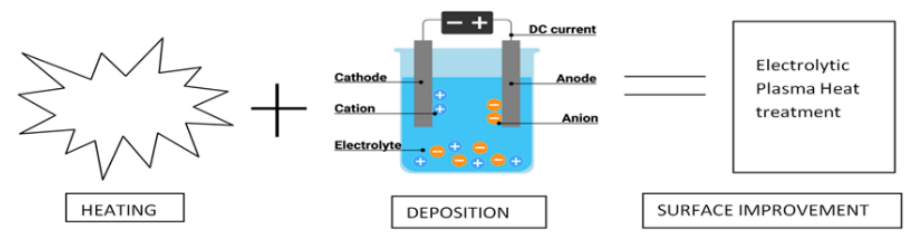

Figure 1. The combination of electrolysis and plasma improves surface properties.

\subsection{Electrolytic Plasma Process.}

In the conventional electrolysis process, the voltage applied across the electrodes is very less as compared to the electrolytic plasma technique in which the voltage is around $200 \mathrm{~V}$ to $400 \mathrm{~V}$. A DC power supply is used to apply a high voltage across the cathode and anode. The workpiece may be a cathode or may be an anode. If cathode works as a work piece, then it is cathodic plasma electrolytic heat treatment, and if anode works as a specimen, then that will be an anodic plasma electrolytic heat-treatment process. As the application of electric potential is very large as compared to conventional electrolysis, the gas liberation density at the surface of the electrode is very much and which leads to continuous gas envelope around the electrode along with an electric discharge. This electric discharge is responsible for extensive heating of the specimen above its recrystallization temperature within a fraction of seconds. The specimen can then be quenched in the same electrolyte by disconnecting the power supply. Various research works show that after the plasma electrolytic heat treatment, the surface properties of steel improved considerably.

The process can be categorized into four main phases, which begins with the formation of vapor around the electrode being treated. Figure 2 shows stages of the electrolytic plasma process in which, after supplying power, the temperature goes on increasing and reaches the highest point when plasma formation occurs. After plasma glows, the power supply is disconnected and electrode quenched in the same electrolyte.

The author studied the relation between current and voltage for AISI 1080 high carbon steel to demonstrate plasma formation in the EPHT process. The spark ignition phase is followed by the continuous plasma envelope which is supposed to be a treatment phase for the metals. Gas liberation phase involves the highest peak of current, and after that increase in voltage, causes an increase in accumulation of charges, and spark ignition occurs. Spark ignition results in heating of electrolyte around the cathode and continuous vapor envelop formed, which results in resistance to the current flow [1].

The cathode can be cooled in the same electrolyte after disconnecting the voltage supply for quenching purposes, which is the requirement of the hardening process. Carbon and nitrogen atoms can be imparted on the surface of electrolytes in the continuous plasma envelope phase. 


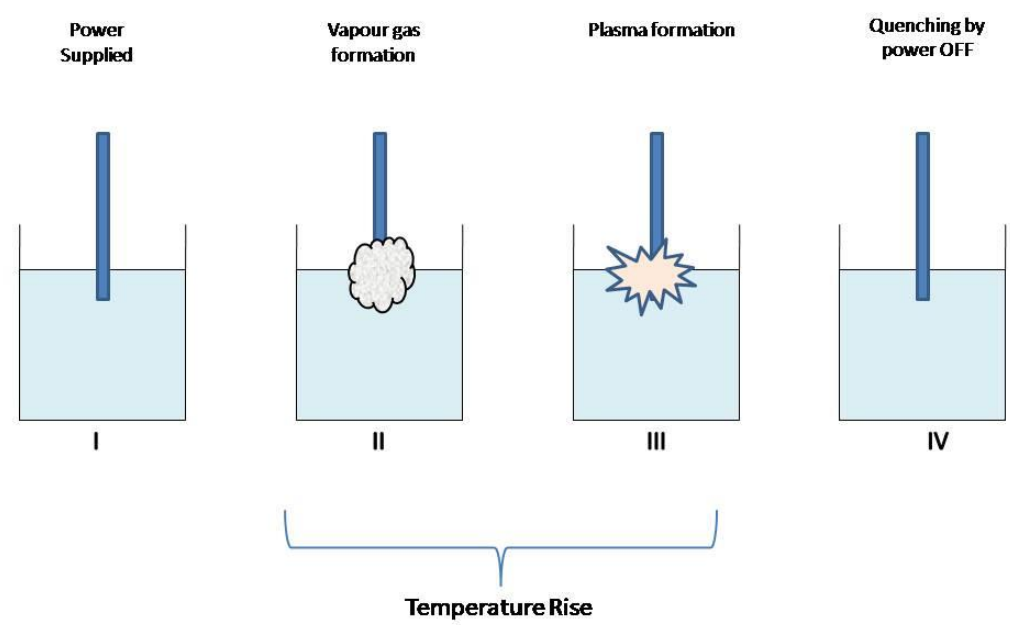

Figure 2. Stages in Electrolytic plasma heat treatment: I) Power on II) Vapour formation III) Plasma formation IV) Quenching

\section{Surface morphology}

\subsection{Alternate heating and cooling method.}

When AISI 4140 was treated with electrolytic plasma thermo cyclic treatment, the stereo microscopic view of the material cross-section clearly indicated the hardened zone and unaffected zone [2]. In this technique, a higher of 300-320 V is applied for a few seconds, and then a lower voltage of 230-250 V applied. Alternate high and low voltage application results in heating and cooling, which results in the development of the high thicked hardened layer within just $42 \mathrm{~s}$. In this way, in a very shorter time, the higher thickness can be obtained by optimizing the process parameters.

The microstructure of the treated specimen depends on heating and cooling cycles in electrolytic plasma hardening. The lower number of cycles results in two layers, namely the hardened zone and transition zone on base material [33]. Higher number of cycle results in three zones namely remelted zone, hardened zone and transition zone on base material. The depth of the hardness increases with the number of cycles. However, there is a requirement of an optimum condition.

\subsection{Deposition methods.}

The deposition of carbon, nitrogen, boron on the surface of steel has been successfully carried out with electrolytic plasma heat treatment [34, 35]. After treating Q235 steel with electrolytic plasma carbonitriding, it was found that the highest thickness of 75 microns was obtained within just $75 \mathrm{~s}$ with hardness value up to the $750 \mathrm{HV}$. When the relation between time and hardness was studied, it was observed that for a higher time, the depth of hardness is higher hardness profile was wider than lower treatment time profile. At higher treatment time, which was more than $75 \mathrm{~s}$, the quality of the layer was deteriorated due to the reticular pattern of the carbide layer [34].

Boronizing of different steel grades steel was carried out by electrolytic plasma process, and it was observed that steel containing more percentage $\mathrm{Cr}$ can exhibit more boron diffusion 
and highe thickness of the boride layer was developed [35]. The maximum hardness for medium carbon steel was obtained up to $1200 \mathrm{HV}$, which was less as compared to the traditional boronizing process, but the thickness of the boride layer was higher and fabricated in a short duration. Tool steel is the backbone material of advanced manufacturing industries, and different technologies have been developing to increase the surface properties of tool steel. Plasma electrolytic nitriding of tool steel has been carried out by using ammonium nitrate and ammonium chloride solution [36]. When tool steel treated with Plasma Electrolytic Nitriding $(\mathrm{PEN})$ it was found that maximum microhardness was obtained $1280 \mathrm{HV}$ with improvement in corrosion resistance.

Commercial grade austenitic stainless steel developed 20-60 micron nitride layer when treated by plasma electrolytic nitriding during 20-60 min in the temperature range of 375 to $480{ }^{\circ} \mathrm{C}$ with manual control of temperature. It was proposed that the process will be more efficient after more accurate process control parameters like the temperature of the sample and composition of electrolyte [37].

\subsection{Surface coating and polishing.}

Plasma electrolytic oxidation was used to fabricate oxide film on the surface of a Titanium alloy by using Ac power source. In this work, PEO film was produced by using a silicate electrolyte. The film produced is having a good combination of thickness, hardness, wear-resistance, and adhesion. The type of electrolyte determines the corrosion resistance property and friction coefficient based on the process of chemical reaction stability of the coating [38]. Alumina coating technique is very effective for improving hardness, wear resistance, and corrosion resistance of steel and aluminum alloys. Plasma electrolysis has been successfully implemented on $\mathrm{BS} \mathrm{Al} 6082$ for $\mathrm{Al}_{2} \mathrm{O}_{3}$ coating. XRD and TEM analyses were conducted to analyze the microstructure of the coated layer. Results have shown that PEO technique successfully improves wear and corrosion resistance of $\mathrm{Al}$ alloy and even better than stainless steel [39].

The polishing process can be integrated with the nitriding process in the same experimental setup by changing the electrolyte and voltage range. The nitriding process and polishing process is the best possible combination of surface improvement technique and successfully achieved by plasma electrolysis technology. Polishing of specimen was carried out after plasma electrolytic nitriding for a very short period of time, such as $2 \mathrm{~min}$. The surface roughness of the PEN treated sample was found to be increased, which was compensated by the polishing process by removing loose parts of oxide layers formation takes place on the surface of the specimen [40]. The polishing process can also be studied for plasma electrolytic carbonizing, electrolytic plasma thermo cyclic treatment, and other plasma electrolysis process.

\section{Ranges of metals being treated}

Ferrous, as well as non-ferrous metals, have been treated by using electrolytic plasma surface treatment. The major focus is given on steel, as it is the backbone material of the manufacturing industry. Different grades of steel have shown positive results for different kinds of surface treatments such as carburizing, nitriding, boronizing, hardening, coating, cleaning, and polishing. Aluminum alloys have also been treated for coating protective surface layers with different materials. 
Table1 shows the ranges of metals being treated with electrolytic plasma processes, and all metals shown significant results after the treatment. Aluminum and titanium alloy are generally treated by plasma electrolytic oxidation for coating purposes, and steel was treated by plasma electrolytic hardening. Different types of steel, such as low carbon steel to highspeed tool steel, have developed high wear resistance and corrosion resistance. For corrosion resistance, plasma electrolytic nitriding was used. Both anodic and cathodic processes were conducted, and both processes are shown positive results. In future Chemical Vapour Deposition, can be replaced with Electrolytic Plasma Oxidation due to its fast response and low equipment cost. The coating and polishing industry should focus on the development of the electrolytic plasma process as significant results have been achieved by Electrolytic Plasma Process in this field. Pulse current electrolytic plasma process, and electrolytic plasma hardening processes are mainly used for hardness and wear resistance without the deposition process. In this case, martensite is formed at the surface of the substrate, which causes an increase in hardness and wears resistance. Nickel-based alloy and ductile iron also shown improvement in wear resistance property. In the case of a tool, the steel electrolytic plasma process has proven a novel process for increasing wear resistance and decreasing surface roughness. The friction coefficient has also been studied by using the plasma electrolytic carburizing process. In all types of metals that are treated by the electrolytic plasma process have shown drastically increment for wear resistance, and it is the best-suited process to increase the wear resistance of components. Thus by using the electrolytic plasma process, we can treat types of steel, aluminum alloys, Nickel alloys, Titanium alloys, and ductile iron effectively.

Table data clearly shows that generally, alloy elements were treated by deposition methods such as nitriding, carbonitriding, boriding, and carburizing. The process is suitable for increasing hardness without modification of the chemical composition as well as by changing the chemical structure of the surface of the specimen. Electrolytic plasma hardening introduces martensite and cementite at the surface of the heat treatment, and electrolytic plasma nitriding introduces nitrides at the surface of the specimen.

Table 1. Ranges of metals being treated by PET and industrial scope.

\begin{tabular}{|c|c|c|c|c|}
\hline Year & Metal & Type of treatment & Results & $\begin{array}{l}\text { Industrial } \\
\text { Scope }\end{array}$ \\
\hline 1997 & $\begin{array}{l}\text { Medium carbon } \\
\text { steel }\end{array}$ & $\begin{array}{l}\text { Pulse current } \\
\text { electrolytic plasma } \\
\text { heat treatment }\end{array}$ & $\begin{array}{l}\text { Martensite found in hardened steel and the highest } \\
\text { heating rate can be achieved by pulse current as } \\
\text { compared to D.C. voltage [ } 41]\end{array}$ & $\begin{array}{l}\text { Toolroom and } \\
\text { press tool die }\end{array}$ \\
\hline 1998 & $\begin{array}{l}\text { High-speed } \\
\text { steel (circular } \\
\text { saw) }\end{array}$ & $\begin{array}{l}\text { Electrolytic } \\
\text { plasma pulse } \\
\text { heating }\end{array}$ & $\begin{array}{l}\text { Service life increases from } 1000 \text { to } 3000 \text { cuts. } \\
\text { Martensite obtained with hardness increased to } 62 \\
\text { HRC [42] }\end{array}$ & $\begin{array}{l}\text { Hex saw and } \\
\text { cutter }\end{array}$ \\
\hline 2002 & $\begin{array}{l}\text { BS Al6082 } \\
\text { Aluminium } \\
\text { alloy }\end{array}$ & $\begin{array}{l}\text { Plasma electrolytic } \\
\text { oxidation }\end{array}$ & Alumina coating was successfully deposited [39] & $\begin{array}{l}\text { Aerospace, } \\
\text { automobile and } \\
\text { aluminum parts } \\
\text { industry }\end{array}$ \\
\hline 2007 & Q235 steel & $\begin{array}{l}\text { Plasma } \\
\text { electrolysis } \\
\text { carbonitriding }\end{array}$ & $\begin{array}{l}\text { When steel treated with } 150 \mathrm{~V} \text { for } 75 \mathrm{~s} \\
\text { carbonitriding layer of } 70 \text {-micron forms with } \\
\text { hardness } 750 \mathrm{HV}[34]\end{array}$ & Machine parts \\
\hline 2008 & $\begin{array}{l}4340,4140, \\
1045,3215 \text { and } \\
1020 \text { steel }\end{array}$ & $\begin{array}{l}\text { Plasma- } \\
\text { electrolysis } \\
\text { boronizing }\end{array}$ & $\begin{array}{l}\text { Greater value of hardness and boron layer } \\
\text { thickness obtained for } 1020 \text { steel[35] }\end{array}$ & Tool steel \\
\hline 2009 & $\begin{array}{l}\text { Medium carbon } \\
\text { steel (AISI } \\
1040)\end{array}$ & $\begin{array}{l}\text { Electrolytic } \\
\text { plasma } \\
\text { thermocyclic } \\
\text { treatment }\end{array}$ & $\begin{array}{l}\text { Reliable microstructure and surface hardness were } \\
\text { obtained on medium carbon steel [43] }\end{array}$ & Machine parts \\
\hline
\end{tabular}




\begin{tabular}{|c|c|c|c|c|}
\hline Year & Metal & Type of treatment & Results & $\begin{array}{l}\text { Industrial } \\
\text { Scope }\end{array}$ \\
\hline 2010 & AISI 4140 steel & $\begin{array}{l}\text { Electrolytic } \\
\text { plasma } \\
\text { thermocyclic } \\
\text { treatment }\end{array}$ & $\begin{array}{l}\text { Thickness of hardness layer obtained for different } \\
\text { thermo cycles and highest thickness obtained for } \\
300-320 \mathrm{~V} \text { in } 42 \mathrm{~s}[3]\end{array}$ & Machine parts \\
\hline 2011 & $\begin{array}{l}\text { AISI } 1045 \\
\text { (CK45) carbon } \\
\text { steel }\end{array}$ & $\begin{array}{l}\text { Plasma electrolytic } \\
\text { nitrocarburizing }\end{array}$ & $\begin{array}{l}\text { Within } 8 \text { to } 9 \text { min at } 200 \mathrm{~V} \text { nitrocarburized layer } \\
\text { formed[44] }\end{array}$ & $\begin{array}{lll}\text { Tool steel and } \\
\text { dies }\end{array}$ \\
\hline 2012 & $\begin{array}{l}\text { 12Cr18Ni10Ti } \\
\text { steel }\end{array}$ & $\begin{array}{l}\text { Electrolytic- } \\
\text { plasma } \\
\text { cementation (EPC) }\end{array}$ & $\begin{array}{l}\text { Within } 7 \text { min carbide layer was formed of } \\
\text { thickness } 45-65 \text { micron[9] }\end{array}$ & $\begin{array}{l}\text { Punch and die of } \\
\text { press tool steel }\end{array}$ \\
\hline 2014 & $\begin{array}{l}\text { Q235 low } \\
\text { carbon steel }\end{array}$ & $\begin{array}{l}\text { Anodic plasma } \\
\text { electrolytic } \\
\text { carburizing }\end{array}$ & $\begin{array}{lrlrr}\text { Carbon diffused } & \text { into } & \text { compound } & \text { layer } \\
\text { successfully, and } & \text { surface } & \text { roughness } & \text { also } \\
\text { reduced[45] } & & & & \end{array}$ & Machine parts \\
\hline 2015 & St 14 steel & $\begin{array}{l}\text { Plasma electrolysis } \\
\text { boronizing }\end{array}$ & $\begin{array}{l}\text { Only above } 20 \% \text { borax in electrolyte shows the } \\
\text { development of the boride layer on component }\end{array}$ & $\begin{array}{l}\text { Automotive } \\
\text { components }\end{array}$ \\
\hline 2016 & T8 carbon steel & $\begin{array}{l}\text { Plasma electrolytic } \\
\text { carburizing }\end{array}$ & $\begin{array}{l}\text { Steel friction coefficient is reduced from } 0.4 \text { to } \\
0.1 \text {, and the wear rate also reduced to } 1 / 4[47]\end{array}$ & $\begin{array}{l}\text { Special purpose } \\
\text { tools }\end{array}$ \\
\hline 2017 & $\begin{array}{l}0.34 \mathrm{C}-1 \mathrm{Cr}-1 \\
\text { Ni-1 Mo-Fe } \\
\text { steel }\end{array}$ & $\begin{array}{l}\text { Electrolyte plasma } \\
\text { nitriding }\end{array}$ & $\begin{array}{l}\text { Chromium and nitrides increase hardness as well } \\
\text { as wear resistance [29] }\end{array}$ & $\begin{array}{ll}\text { Tool } & \text { steel } \\
\text { industry } & \end{array}$ \\
\hline 2018 & T8 carbon steel & $\begin{array}{l}\text { Cathodic plasma } \\
\text { electrolysis }\end{array}$ & $\begin{array}{l}\text { Significantly improved the wear } \\
\text { the resistance of carbon steel [27] }\end{array}$ & Machine parts \\
\hline 2019 & Ductile Iron & $\begin{array}{l}\text { Electrolytic } \\
\text { Plasma Hardening }\end{array}$ & $\begin{array}{l}1050 \mathrm{HV} \text { hardness achieved with a decrease in } \\
\text { wear rate from } 4.74 \times 10^{-5} \text { to } 0.968 \times 10^{-5} \mathrm{~mm}^{3} / \mathrm{m}\end{array}$ & $\begin{array}{l}\text { Piping, the Pump } \\
\text { housing industry }\end{array}$ \\
\hline 2019 & $\begin{array}{l}\text { Nickel-based } \\
\text { K418 } \\
\text { superalloy }\end{array}$ & $\begin{array}{l}\text { Cathodic } \\
\text { plasma electrolytic } \\
\text { deposition }\end{array}$ & $\begin{array}{l}\text { Successfully deposited } \mathrm{Si} \text { into the surface of the } \\
\text { sample for improving layer mechanical properties } \\
\text { at high temperature [48]. }\end{array}$ & Coating industry \\
\hline 2019 & $\begin{array}{l}\text { VT6 Titanium } \\
\text { alloy }\end{array}$ & $\begin{array}{l}\text { Plasma } \\
\text { Electrolytic } \\
\text { Oxidation }\end{array}$ & $\begin{array}{l}\text { After treatment, } 80 \mu \mathrm{m} \text { thick titanium oxide layer } \\
\text { was formed with an increase in wear resistance. }\end{array}$ & $\begin{array}{l}\text { Aerospace } \\
\text { Industry and } \\
\text { Biomedical } \\
\text { industry }\end{array}$ \\
\hline
\end{tabular}

\section{Future scope in the industry}

\subsection{Press tool industry.}

Electrolytic plasma treatment has shown significant positive results on various types of tool steels. In the press tool industry wear resistance and corrosion resistance, both are necessary, and these properties can be achieved by the electrolytic plasma process. Carbon was successfully transferred on low carbon steel surface by electrolytic plasma carburizing, which results in an increase in hardness up to $700 \mathrm{HV}$, and also anodic process results in reducing surface roughness [45]. The process can be modified for complicated components in which carburizing is needed only on a small portion of the component.

\subsection{Biomedical implants.}

Titanium alloy is mostly used in biomedical implants, and many researchers have successfully carried out the surface modification of $\mathrm{Ti}$ by plasma electrolytic coating and polishing. Surface properties of V22 Titanium alloy have been improved significantly by plasma electrolytic nitriding with 460HV hardness and $20 \mu \mathrm{m}$ hardened layer [23].

\subsection{Automobile industry.}

Cast iron-based camshaft shown 50-60 HRC after treating with electrolytic plasma hardening [20]. Automotive components like camshafts can be treated with electrolytic plasma processes to induce necessary hardness and wear resistance. Also, performance study may be 
carried out for conventionally treated components, and PEP treated components. AISI 4140 is the largest and most common material used in tool holders, dies, jigs, and fixtures. Overall mechanical prosperities of this steel have been successfully improved by the electrolytic plasma process $[3,43]$.

\subsection{Aerospace industry.}

Aluminum, such as BS Al 6082, has also been treated with plasma electrolytic oxidation in which a protective layer of $\mathrm{Al} 2 \mathrm{O} 3$ was successfully deposited on the aluminum surface. The wear and corrosion resistance were improved significantly [39]. Aluminum and its alloy are used in large quantities in the aerospace manufacturing industry. The electrolytic plasma process can be considered for the growth of the aerospace industry in terms of quality and production.

\section{Summary}

Electrolytic Plasma Technology is a novel method for improving surface properties of the low, medium, and high carbon steels. For aluminum alloy also EPT shows positive results for the fabrication coating layer of different materials such as alumina and silicon. Nickelbased Superalloys have also been treated and show improvement in surface properties. The setup required for the process is economical, and no environmental hazardous occurs. The time required to introduce desire properties is in the range of $60 \mathrm{~s}$ to $5 \mathrm{~min}$, which very less as compared to current surface treatments. EPT is a dynamic process, which means hardening, deposition, coating, cleaning, polishing can be done in the same setup with little modification. The coating process can be explored for EPT for different materials where surface properties play an important role. Process parameter optimization, advanced sensors, and data logger system can control the process in a more accurate sense, and better results can be obtained by EPT.

Following conclusions may be drawn from this study:

Electrolytic Plasma hardening and nitriding can be done in the same apparatus within a short time in which hardening is done for hardness improvement, and nitriding is done for corrosion resistance. Electrolytic plasma nitriding and polishing can be done one after another in the same setup.

Surface roughness is affected by the type of electrolytic plasma process. In the cathodic electrolytic plasma process, the surface roughness increases, and in anodic electrolytic plasma process, the surface roughness decreases.

For corrosion resistance, we can increase the corrosion resistance of the metal even greater thans stainless steel.

A coating layer of very small thickness, which is in the range of nanometres, can also be deposited successfully on the surface of metals by the electrolytic plasma process.

\section{Funding}

This research received no external funding.

\section{Acknowledgments}

All authors of this review paper acknowledge the researchers mentioned in this review and across the entire globe for their valuable working on the electrolytic plasma process. 


\section{Conflicts of Interest}

The authors declare no conflict of interest.

\section{References}

1. Gupta, P.; Tenhundfeld, G.; Daigle, E.O.; Ryabkov, D. Electrolytic plasma technology: Science and engineering-An overview. Surface and Coatings Technology 2007, 201, 8746-8760, https://doi.org/10.1016/j.surfcoat.2006.11.023.

2. Luk, S.F.; Leung, T.P.; Miu, W.S.; Pashby, I. A study of the effect of average preset voltage on hardness during electrolytic surface-hardening in aqueous solution. Journal of Materials Processing Technology 1999, 91, 245249,https://doi.org/10.1016/S0924-0136(98)00441-5.

3. Cenk Kumruoğlu, L.; Özel, A. Surface Modification of AISI 4140 Steel Using Electrolytic Plasma Thermocyclic Treatment. Materials and Manufacturing Processes 2010, 25, 923931,https://doi.org/10.1080/10426911003720839.

4. Karimi Zarchi, M.; Shariat, M.H.; Dehghan, S.A.; Solhjoo, S. Characterization of nitrocarburized surface layer on AISI 1020 steel by electrolytic plasma processing in an urea electrolyte. Journal of Materials Research and Technology 2013, 2, 213-220, https://doi.org/10.1016/j.jmrt.2013.02.011.

5. Zagonel, L.F.; Bettini, J.; Basso, R.L.O.; Paredez, P.; Pinto, H.; Lepienski, C.M.; Alvarez, F. Nanosized precipitates in H13 tool steel low temperature plasma nitriding. Surface and Coatings Technology 2012, 207, 72-78,https://doi.org/10.1016/j.surfcoat.2012.05.081.

6. Skakov, M.; Rakhadilov, B.; Sheffler, M. Influence of Electrolyte Plasma Treatment on Structure, Phase Composition and Microhardness of Steel P6M5. Key Engineering Materials 2013, 531-532, 627631,https://doi.org/10.4028/www.scientific.net/KEM.531-532.627.

7. Ayday, A.; Durman, M. Wear properties of aisi 4140 steel modified with electrolytic-plasma technology. Materiali in Tehnologije2013, 47, 177-180.

8. Liu, R.; Li, X.; Hu, X.; Dong, H. Surface modification of a medical grade Co-Cr-Mo alloy by low-temperature plasma surface alloying with nitrogen and carbon. Surface and Coatings Technology 2013, 232, 906-911, https://doi.org/10.1016/j.surfcoat.2013.06.122.

9. Kurbanbekov, Sherzod\&Skakov, Mazhyn\& Scheffler, Michael \&Naltaev, Azret. (2012). Changes of Mechanical Properties of Steel 12Cr18Ni10Ti after Electrolytic-Plasma Cementation. Advanced Materials Research.601.59-63. https://doi.org/10.4028/www.scientific.net/AMR.601.59.

10. Liang, J. A study on the cleaning and modification of metal surfaces by direct current cathodic electrolytic plasma process LSU Doctoral Dissertations. 2013; pp. 618.

11. Skonieski, A.F.O.; Santos, G.R.d.; Hirsch, T.K.; Rocha, A.d.S. Metallurgical response of an AISI 4140 steel to different plasma nitriding gas mixtures. Materials Research 2013, 16, 884-890,https://doi.org/10.1590/S151614392013005000073.

12. Duradji, V.N.; Kaputkin, D.; Duradji, A. Aluminum Treatment in the Electrolytic Plasma During the Anodic Process. Journal of Engineering Science and Technology Review 2017, 10, 8184,https://doi.org/10.25103/jestr.103.11.

13. Duradji, V.; Kaputkin, D. Metal Surface Treatment in Electrolyte Plasma during Anodic Process. Journal of The Electrochemical Society 2016, 163, E43-E48, https://doi.org/10.1149/2.0011603jes.

14. Dewan, M.W.; Liang, J.; Wahab, M.A.; Okeil, A.M. Effect of post-weld heat treatment and electrolytic plasma processing on tungsten inert gas welded AISI 4140 alloy steel. Materials \& Design (1980-2015) 2014, 54, 6-13, https://doi.org/10.1016/j.matdes.2013.08.035.

15. Kashapov, L.N.; Kashapov, N.F.; Kashapov, R.N.; Semushin, V.D. Changes of thermal balance in a plasmaelectrolyte system according to the shape of the applied voltage. Journal of Physics: Conference Series 2016, 669,https://doi.org/10.1088/1742-6596/669/1/012028.

16. Ozel, A.; Kumruoglu, L.C. Wear Performance of Hardened 1.2333 Cold work Tool Steel by Plasma Electrolysis. Acta physica Polonica A2014, 125,https://doi.org/10.12693/APhysPolA.125.304.

17. cheuer, C.J.; Cardoso, R.P.; Brunatto, S.F. Low-temperature Plasma Assisted Thermochemical Treatments of AISI 420 Steel: Comparative Study of Obtained Layers. Materials Research 2015, 18, 13921399,https://doi.org/10.1590/1516-1439.013815.

18. Rakhadilov, B.; Zhurerova, L.; Pavlov, A. Method of Electrolyte-Plasma Surface Hardening of 65G and 20GL Low-Alloy Steels Samples. IOP Conference Series: Materials Science and Engineering 2016, 142, https://doi.org/10.1088/1757-899X/142/1/012028.

19. Belkin, P.N.; Kusmanov, S.A. Plasma electrolytic hardening of steels: Review. Surface Engineering and Applied Electrochemistry 2016, 52, 531-546, https://doi.org/10.3103/S106837551606003X.

20. Dayanç, A.; Karaca, B.; Kumruoğlu, L. The Cathodic Electrolytic Plasma Hardening of Steel and Cast Iron Based Automotive Camshafts. Acta Physica Polonica A2017,131, 374379,https://doi.org/10.12693/APhysPolA.131.374.

21. Ozbek, Y. Effect of Heat Treatment and Pulse Plasma Process on Surface Properties of Steels. Acta Physica Polonica A. 2017, 131, 182-185, https://doi.org/10.12693/APhysPolA.131.182. 
22. Kusmanov, S.A.; Dyakov, I.G.; Kusmanova, Y.V.; Belkin, P.N. Surface Modification of Low-Carbon Steels by Plasma Electrolytic Nitrocarburising. Plasma Chemistry and Plasma Processing 2016, 36, 1271-1286, https://doi.org/10.1007/s11090-016-9724-3.

23. Smirnov, A.A.; Kusmanov, S.A.; Kusmanova, I.A.; Belkin, P.N. Effect of electrolyte depletion on the characteristics of the anodic plasma electrolytic nitriding of a VT22 titanium alloy. Surface Engineering and Applied Electrochemistry 2017, 53, 413-418,https://doi.org/10.3103/S106837551705012X.

24. Belkin, P.N.; Kusmanov, S.A. Plasma electrolytic nitriding of steels. Journal of Surface Investigation: X-ray, Synchrotron and Neutron Techniques 2017, 11, 767-789,https://doi.org/10.1134/S1027451017020045.

25. Hussein, R.O.; Nie, X.; Northwood, D.O.; Yerokhin, A.; Matthews, A. Spectroscopic study of electrolytic plasma and discharging behaviour during the plasma electrolytic oxidation (PEO) process. Journal of Physics D: Applied Physics 2010, 43.

26. Belkin, P.N.; Kusmanov, S.A.; Dyakov, I.G.; Silkin, S.A.; Smirnov, A.A. Increasing Wear Resistance of Titanium Alloys by Anode Plasma Electrolytic Saturation with Interstitial Elements. Journal of Materials Engineering and Performance 2017, 26, 2404-2410,https://doi.org/10.1007/s11665-017-2655-1.

27. Wu, J.; Dong, L.; Deng, J.; Hou, D.; Li, G.; Li, D.; Xue, W. Direct growth of oxide layer on carbon steel by cathodic plasma electrolysis. Surface and Coatings Technology 2018, 338, 63-68, https://doi.org/10.1016/j.surfcoat.2018.01.080.

28. Noori, S.M.; Dehghanian, C. Characterization of nitrocarburized coating by plasma electrolytic saturation. Acta MetallurgicaSlovaca2018, 24,https://doi.org/10.12776/ams.v24i1.957.

29. Popova, N.; Erygina, L.; Nikonenko, E.; Skakov, M. Phase composition of perlite steel modified by electrolyte plasma nitriding. AIP Conference Proceedings 2017, 1899,https://doi.org/10.1063/1.5009847.

30. Kusmanov, S.A.; Tambovskiy, I.V.; Naumov, A.R.; Dyakov, I.G.; Belkin, P.N. Anode plasma electrolytic boronitrocarburising of low-carbon steel. Surface Engineering and Applied Electrochemistry 2015, 51, 462467,https://doi.org/10.3103/S1068375515050099.

31. Çavuşlu, F.; Usta, M. Kinetics and mechanical study of plasma electrolytic carburizing for pure iron. Applied Surface Science 2011, 257, 4014-4020, https://doi.org/10.1016/j.apsusc.2010.11.167.

32. Belkin, P.N.; Naumov, A.; Shadrin, S.; Dyakov, I.G.; Zhirov, A.; Kusmanov, S.A.; Mukhacheva, T. Anodic Plasma Electrolytic Saturation of Steels by Carbon and Nitrogen. Advanced Materials Research 2013, 704, 3742,https://doi.org/10.4028/www.scientific.net/AMR.704.37.

33. Ayday, A.; Durman, M. Wear performance of ductile iron after electrolytic plasma hardening. Metallic Materials 2019, 57, 19-26,https://doi.org/10.4149/km_2019_1_19.

34. Shen, D.J.; Wang, Y.L.; Nash, P.; Xing, G.Z. A novel method of surface modification for steel by plasma electrolysis carbonitriding. Materials Science and Engineering: A 2007, 458, 240-243, https://doi.org/10.1016/j.msea.2006.12.067.

35. Béjar, M.A.; Henríquez, R. Surface hardening of steel by plasma-electrolysis boronizing. Materials \& Design 2009, 30, 1726-1728, https://doi.org/10.1016/j.matdes.2008.07.006.

36. Dyakov, I.G.; Burov, S.V.; Belkin, P.N.; Rozanov, E.V.; Zhukov, S.A. Increasing wear and corrosion resistance of tool steel by anodic plasma electrolytic nitriding. Surface and Coatings Technology 2019, 362, 124-131, https://doi.org/10.1016/j.surfcoat.2019.01.107.

37. Roy, A.; Tewari, R.K.; Sharma, R.C.; Shekhar, R. Feasibility study of aqueous electrolyte plasma nitriding. Surface Engineering 2007, 23, 243-246,https://doi.org/10.1179/174329407X215285.

38. Yerokhin, A.L.; Nie, X.; Leyland, A.; Matthews, A. Characterisation of oxide films produced by plasma electrolytic oxidation of a Ti-6Al-4V alloy. Surface and Coatings Technology 2000, 130, 195-206, https://doi.org/10.1016/S0257-8972(00)00719-2.

39. Nie, X.; Meletis, E.I.; Jiang, J.C.; Leyland, A.; Yerokhin, A.L.; Matthews, A. Abrasive wear/corrosion properties and TEM analysis of A12O3 coatings fabricated using plasma electrolysis. Surface and Coatings Technology 2002, 149, 245-251,https://doi.org/10.1016/S0257-8972(01)01453-0.

40. Kusmanov, S.; Zhirov, A.; Kusmanova, I.; Belkin, P. Aspects of anodic plasma electrolytic polishing of nitrided steel. Surface Engineering 2019, 35, 507-511, https://doi.org/10.1080/02670844.2017.1406574.

41. Luk, S.F.; Leung, T.P.; Miu, W.S.; Pashby, I. Heating performance of electrolytic heat-treatment in aqueous solution by pulse current. Journal of Materials Processing Technology 1997, 63, 833-838, https://doi.org/10.1016/S0924-0136(96)02734-3.

42. Tyulyapin, A.N.; Tyurin, Y.N.; Traino, A.I.; Yusupov, V.S. Electrolyte-plasma hardening of circular saws. Metal Science and Heat Treatment 1998,40, 11-13,https://doi.org/10.1007/BF02468498.

43. Kumruoglu, L.C.; Becerik, D.A.; Ozel, A.; Mimaroglu, A. Surface Modification of Medium Carbon Steel by Using Electrolytic Plasma Thermocyclic Treatment. Materials and Manufacturing Processes 2009, 24, 781785, https://doi.org/10.1080/10426910902813034.

44. Rastkar, A.R.; Shokri, B. Surface modification and wear test of carbon steel by plasma electrolytic nitrocarburizing. Surface and Interface Analysis 2012, 44, 342-351,https://doi.org/10.1002/sia.3808.

45. Kusmanov, S.A.; Shadrin, S.Y.; Belkin, P.N. Carbon transfer from aqueous electrolytes to steel by anode plasma electrolytic carburising. Surface and Coatings Technology 2014, 258, 727-733, https://doi.org/10.1016/j.surfcoat.2014.08.005.

46. Tavakoli, H.; Mousavi Khoie, S.M.; Rasooli, F.; Marashi, S.P.H.; Momeni, F. Electrochemical and physical 
characteristics of the steel treated by plasma-electrolysis boronizing. Surface and Coatings Technology 2015, 276, 529-533,https://doi.org/10.1016/j.surfcoat.2015.06.020.

47. Wu, J.; Wang, B.; Zhang, Y.; Liu, R.; Xia, Y.; Li, G.; Xue, W. Enhanced wear and corrosion resistance of plasma electrolytic carburized layer on T8 carbon steel. Materials Chemistry and Physics 2016, 171, 50-56, https://doi.org/10.1016/j.matchemphys.2015.09.047.

48. Xue, J.; Wang, D.; Li, M.; Jia, R. Preparation of silicon-modified gamma alumina coating through cathodic plasma electrolytic deposition. Ceramics International 2019, 45, 19345-19350, https://doi.org/10.1016/j.ceramint.2019.06.186.

49. Kusmanov, S.A.; Smirnov, A.A.; Kusmanova, Y.V.; Belkin, P.N. Anode plasma electrolytic nitrohardening of medium carbon steel. Surface and Coatings Technology 2015, 269, 308-313, https://doi.org/10.1016/j.surfcoat.2014.12.033.

50. Kusmanov, S.A.; Kusmanova, Y.V.; Naumov, A.R.; Belkin, P.N. Features of anode plasma electrolytic nitrocarburising of low carbon steel. Surface and Coatings Technology 2015, 272, 149-157, https://doi.org/10.1016/j.surfcoat.2015.04.011.

51. Belkin, P.N.; Kusmanov, S.A.; Smirnov, A.A. Plasma Electrolytic Hardening and Nitrohardening of Medium

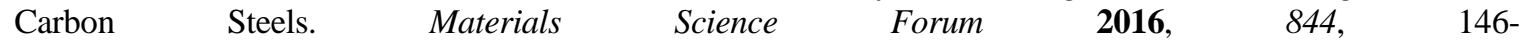
152,https://doi.org/10.4028/www.scientific.net/msf.844.146.

52. Ablyaz, T.; Muratov, K.; Ushomirskaya, L.; Zarubin, D.; Sidhu, S. Electrolytic plasma polishing technique for improved surface finish of ED machined components. Engineering Solid Mechanics 2019, 7, 131-136, https://doi.org/10.5267/j.esm.2019.3.003.

53. Rakoch, A.G.; Van Truong, P.; Gladkova, A.A.; Predein, N.A. Phase Composition and Wear Resistance of Coatings Formed on the VT6 Titanium Alloy by Plasma Electrolytic Oxidation. Russian Journal of NonFerrous Metals 2019, 60, 200-206, https://doi.org/10.3103/S106782121902010X.

54. Yongfu Zhang, Aiming Bu, Yan Xiang, Yunjie Yang, Weiwei Chen, Huanwu Cheng, Lu Wang,Improving corrosion resistance of carbonyl iron powders by plasma electrolytic deposition, Materials \& Design, Volume 188,2020,108480,ISSN 0264-1275, https://doi.org/10.1016/j.matdes.2020.108480.

55. Tabieva, E.E.; Zhurerova, L.G.; Baizhan, D. Influence of Electrolyte-Plasma Hardening Technological Parameters on the Structure and Properties of Banding Steel 2. Key Engineering Materials 2020, 839, 57-62, https://doi.org/10.4028/www.scientific.net/kem.839.57.

56. Popova, N.A.; Potekaev, A.I.; Nikonenko, E.L.; Klopotov, A.A.; Bayatanova, L.B.; Nikonenko, A.V.; Kislitsin, S.B. Phase Composition and Thin Structure of Steel Surface after Plasma Electrolytic Carbonitriding. Russian Physics Journal 2020, 62, 1794-1800, https://doi.org/10.1007/s11182-020-01908-9.

57. Satbayeva, Z.A.; Zhurerova, L.G.; Tabieva, E.E. Plasma Electrolytic Cementation of 0.3C-1Cr-1Mn-1Si-Fe Steel. Key Engineering Materials 2020, 839, 196-202,https://doi.org/10.4028/www.scientific.net/kem.839.196.

58. Kellogg, H.H. Anode Effect in Aqueous Electrolysis. Journal of The Electrochemical Society 1950, 97, 133,https://doi.org/10.1149/1.2777980.

59. Hickling, A. Modern Aspects of Electrochemistry. Volume 6, Butterworths, Springer Science \& Business Media.

60. Yerokhin, A.L.; Nie, X.; Leyland, A.; Matthews, A.; Dowey, S.J. Plasma electrolysis for surface engineering. Surface and Coatings Technology 1999, 122, 73-93, https://doi.org/10.1016/S0257-8972(99)00441-7.

61. Hussein, R.O.; Zhang, P.; Nie, X.; Xia, Y.; Northwood, D.O. The effect of current mode and discharge type on the corrosion resistance of plasma electrolytic oxidation (PEO) coated magnesium alloy AJ62. Surface and Coatings Technology 2011, 206, 1990-1997, https://doi.org/10.1016/j.surfcoat.2011.08.060.

62. Sengupta, S.K.; Singh, O.P. Contact glow discharge electrolysis: a study of its onset and location. Journal of Electroanalytical Chemistry and Interfacial Electrochemistry 1991, 301, 189-197, https://doi.org/10.1016/0022-0728(91)85469-6.

63. Cionea, C. Microstructural Evolution Of Surface Layers During Electrolytic Plasma Processing. 2010.

64. Arrabal, R.; Matykina, E.; Viejo, F.; Skeldon, P.; Thompson, G.E. Corrosion resistance of WE43 and AZ91D magnesium alloys with phosphate PEO coatings. Corrosion Science 2008, 50, 17441752,https://doi.org/10.1016/j.corsci.2008.03.002.

65. Mashtalyar, D.V.; Gnedenkov, S.V.; Sinebryukhov, S.L.; Imshinetskiy, I.M.; Gnedenkov, A.S.; Bouznik, V.M. Composite coatings formed using plasma electrolytic oxidation and fluoroparaffin materials. Journal of Alloys and Compounds 2018, 767, 353-360,https://doi.org/10.1016/j.jallcom.2018.07.085.

66. Yerokhin, A.L.; Nie, X.; Leyland, A.; Matthews, A.; Dowey, S.J. Plasma electrolysis for surface engineering. Surface and Coatings Technology 1999, 122, 73-93, https://doi.org/10.1016/S0257-8972(99)00441-7.

67. Sengupta, S.K.; Singh, O.P. Contact glow discharge electrolysis: a study of its chemical yields in aqueous inerttype electrolytes. Journal of Electroanalytical Chemistry 1994, 369, 113-120,https://doi.org/10.1016/00220728(94)87089-6.

68. Rudnev, V.S.; Yarovaya, T.P.; Nedozorov, P.M.; Mansurov, Y.N. Wear-resistant oxide coatings on aluminum alloy formed in borate and silicate aqueous electrolytes by plasma electrolytic oxidation. Protection of Metals and Physical Chemistry of Surfaces 2017, 53, 466-474,https://doi.org/10.1134/S2070205117030200.

69. Timoshenko, A.V.; Magurova, Y.V. Investigation of plasma electrolytic oxidation processes of magnesium alloy MA2-1 under pulse polarisation modes. Surface and Coatings Technology 2005, 199, 135-140, 
https://doi.org/10.1016/j.surfcoat.2004.09.036.

70. Lou, B.S.; Lee, J.W.; Tseng, C.M.; Lin, Y.Y.; Yen, C.A. Mechanical property and corrosion resistance evaluation of AZ31 magnesium alloys by plasma electrolytic oxidation treatment: Effect of MoS2 particle addition. Surface and Coatings Technology 2018, 350, 813-822, https://doi.org/10.1016/j.surfcoat.2018.04.044.

71. Gnedenkov, S.V.; Sinebryukhov, S.L.; Tkachenko, I.A.; Mashtalyar, D.V.; Ustinov, A.Y.; Samokhin, A.V.; Tsvetkov, Y.V. Magnetic properties of surface layers formed on titanium by plasma electrolytic oxidation. Inorganic Materials: Applied Research 2012, 3, 151-156,https://doi.org/10.1134/S2075113312020062.

72. White, L.; Koo, Y.; Yun, Y.; Sankar, J. TiO 2 Deposition on AZ31 Magnesium Alloy Using Plasma Electrolytic Oxidation. Journal of Nanomaterials 2013, 2013https://doi.org/10.1155/2013/319437.

73. Pogrebnyak, A.D.; Kaverina, A.S.; Kylyshkanov, M.K. Electrolytic plasma processing for plating coatings and treating metals and alloys. Protection of Metals and Physical Chemistry of Surfaces 2014, 50, 72-87, https://doi.org/10.1134/S2070205114010092.

74. Shadrin, S.Y.; Belkin, P.N. Analysis of models for calculation of temperature of anode plasma electrolytic heating. International Journal of Heat and Mass Transfer 2012, 55, 179-186, https://doi.org/10.1016/j.ijheatmasstransfer.2011.09.001.

75. Ren, J.; Yao, M.; Yang, W.; Li, Y.; Gao, J. Recent progress in the application of glow-discharge electrolysis plasma. Central European Journal of Chemistry 2014, 12, 1213-1221, https://doi.org/10.2478/s11532-0140575-6.

76. Sengupta, S.K.; Srivastava, A.K.; Singh, R. Contact glow discharge electrolysis: a study on its origin in the light of the theory of hydrodynamic instabilities in local solvent vaporisation by Joule heating during electrolysis. Journal of Electroanalytical Chemistry 1997, 427, 23-27,https://doi.org/10.1016/S0022-0728(96)05044-9.

77. D’yakov, I.G.; Belkin, V.S.; Shadrin, S.Y.; Belkin, P.N. Peculiarities of heat transfer at anodic plasma electrolytic treatment of cylindrical pieces. Surface Engineering and Applied Electrochemistry 2014, 50, 346355, https://doi.org/10.3103/S1068375514040061.

78. Belkin, P.N.; Pasinkovskii, E.A. Heat treatment and case hardening of steels subjected to heat in electrolyte solutions. Metal Science and Heat Treatment 1989, 31, 331-337,https://doi.org/10.1007/BF00801655.

79. Pogrebnyak, A.D.; Tyurin, Y.N. Modification of material properties and coating deposition using plasma jets. Physics-Uspekhi2005, 48, 487-514,https://doi.org/10.1070/PU2005v048n05ABEH002055.

80. Klapkiv, M.D. State of an electrolytic plasma in the process of synthesis of oxides based on aluminum. Materials Science 1996, 31, 494-499,https://doi.org/10.1007/BF00559144.

81. BaratiDarband, G.; Aliofkhazraei, M.; Hamghalam, P.; Valizade, N. Plasma electrolytic oxidation of magnesium and its alloys: Mechanism, properties and applications. Journal of Magnesium and Alloys 2017, 5, 74-132,https://doi.org/10.1016/j.jma.2017.02.004.

82. Pogrebnjak, A.D.; Kul'ment'eva, O.P.; Kobzev, A.P.; Tyurin, Y.N.; Golovenko, S.I.; Boiko, A.G. Mass transfer and doping during electrolyte-plasma treatment of cast iron. Technical Physics Letters 2003, 29, 312-315, https://doi.org/10.1134/1.1573301.

83. Electrolytic Plasma Processing for Sequential Cleaning and Coating Deposition for Cadmium Plating Replacement, Project WP-1406 Annual Report to U.S. Department of Defense Strategic Environmental Research and Development Program, December 2005.

84. Luk, S.F.; Leung, T.P.; Miu, W.S.; Pashby, I. Development of electrolytic heat-treatment in aqueous solution. Journal of Materials Processing Technology 1998, 84, 189-192, https://doi.org/10.1016/S0924-0136(98)000867.

85. Bayati, M.R.; Molaei, R.; Janghorban, K. Surface Modification of AISI 1045 Carbon Steel by the Electrolytic Plasma Process. Metallurgical and Materials Transactions A 2010, 41, 906-911,https://doi.org/10.1007/s11661009-0165-y.

86. Belkin, P.N.; Kusmanov, S.A. Plasma Electrolytic Boriding of Steels and Titanium Alloys. Surface Engineering and Applied Electrochemistry 2019, 55, 1-30, https://doi.org/10.3103/S106837551901006X.

87. Makishi, T.; Nakata, K. Surface hardening of nickel alloys by means of plasma nitriding. Metallurgical and Materials Transactions A 2004, 35, 227-238,https://doi.org/10.1007/s11661-004-0123-7.

88. Stavrev, D.S.; Kaputkina, L.M.; Kirov, S.K.; Shamonin, Y.V.; Prokoshkina, V.G. Effect of plasma-arc treatment on structural transformations and surface hardening of carbon and alloyed steels. Metal Science and Heat Treatment 1996, 38, 382-385, https://doi.org/10.1007/BF01395643.

89. Aliofkhazraei, M.; Rouhaghdam, A.S.; Roohzendeh, M. Study of bipolar pulsed plasma electrolytic carbonitriding on nanostructure of compound layer for a gamma Ti-Al alloy. Frontiers of Materials Science in China 2008, 2, 48-54,https://doi.org/10.1007/s11706-008-0009-5.

90. Aliofkhazraei, M.; Rouhaghdam, A.S. Study of bipolar pulsed nanocrystalline plasma electrolytic carbonitriding on nanostructure of compound layer. Russian Journal of Non-Ferrous Metals 2008, 49, 212218,https://doi.org/10.3103/S1067821208030152.

91. Belkin, P.N.; Borisov, A.M.; Kusmanov, S.A. Plasma electrolytic saturation of titanium and its alloys with light elements. Journal of Surface Investigation. X-ray, Synchrotron and Neutron Techniques 2016, 10, 516-535, https://doi.org/10.1134/S1027451016030058.

92. Kolomeichenko, A.V.; Kravchenko, I.N. Elemental Composition and Microhardness of the Coatings Prepared on Faced Aluminum Alloys by Plasma Electrolytic Oxidation in a Silicate-Alkaline Electrolyte. Russian 
Metallurgy (Metally) 2019, 2019, 1410-1413, https://doi.org/10.1134/S0036029519130147.

93. Kuznetsov, Y.A.; Kravchenko, I.N.; Goncharenko, V.V.; Glinskii, M.A. Machining of the Ceramic Oxide Coating Formed by Plasma Electrolytic Oxidation. Russian Metallurgy (Metally) 2018, 2018, 1268-1272, https://doi.org/10.1134/S003602951813013X.

94. Kovalenko, V.S., Verkhoturov, A.D., Golovko, L.F. et al. Laser surface hardening and electric-spark surface hardening of materials. J Russ Laser Res 9, 1-175 (1988). https://doi.org/10.1007/BF01120344 .

95. Aver'yanov, E.E.; Galimzyanov, R.M.; Gilyazova, K.Z.; Popov, V.A.; Rabinovich, A.V.; Shagiakhmetov, R.A. Use of plasma-electrolytic anodizing to produce thick-layer coatings on aluminum alloys. Chemical and Petroleum Engineering 1991, 27, 230-232,https://doi.org/10.1007/BF01150229.

96. Imbirovich, N.Y.; Klapkiv, M.D.; Posuvailo, V.M.; Povstyanoi, O.Y. Properties of Ceramic Oxide Coatings on Magnesium and Titanium Alloys Synthesized in Electrolytic Plasma. Powder Metallurgy and Metal Ceramics 2015, 54, 47-52, https://doi.org/10.1007/s11106-015-9678-7.

97. Zhirov, A.V.; Belkin, P.N.; Shadrin, S.Y. Heat Transfer in the Anode Region in Plasma-Electrolytic Heating of a Cylindrical Sample. Journal of Engineering Physics and Thermophysics2017, 90, 862-872, https://doi.org/10.1007/s10891-017-1635-5.

98. Kusmanov, S.A.; Tambovskii, I.V.; Naumov, A.R.; D’yakov, I.G.; Kusmanova, I.A.; Belkin, P.N. Anodic electrolytic-plasma borocarburizing of low-carbon steel. Protection of Metals and Physical Chemistry of Surfaces 2017, 53, 488-494, https://doi.org/10.1134/S2070205117030121.

99. Shadrin, S.Y.; Belkin, P.N.; Tambovskiy, I.V.; Kusmanov, S.A. Physical Features of Anodic Plasma Electrolytic Carburising of Low-Carbon Steels. Plasma Chemistry and Plasma Processing 2020, 40, 549-570, https://doi.org/10.1007/s11090-020-10062-6.

100.Liang, J.; Wahab, M.A.; Guo, S.M. Corrosion Behavior of SS 304 with Ball Milling and Electrolytic Plasma Treatment in $\mathrm{NaCl}$ Solution. In Proceedings of Mechanics of Time-Dependent Materials and Processes in Conventional and Multifunctional Materials, Volume 3, New York, NY, 2011; pp. 7380,https://doi.org/10.1007/978-1-4614-0213-8_11.

101. Klapkiv, M.D.; Chuchmarev, O.S.; Sydor, P.Y.; Posuvailo, V.M. Thermodynamics of the interaction of aluminum, magnesium, and zirconium with components of an electrolytic plasma. Materials Science 2000, 36, 66-79, https://doi.org/10.1007/BF02805119.

102.Rudnev, V.S.; Yarovaya, T.P.; Kilin, K.N.; Malyshev, I.V. Plasma-electrolytic oxidation of valve metals in $\mathrm{Zr}(\mathrm{IV})$-containing electrolytes. Protection of Metals and Physical Chemistry of Surfaces 2010, 46, 456-462, https://doi.org/10.1134/S2070205110040118.

103. Kumari, R.; Blawert, C.; Majumdar, J.D. Microstructures and Properties of Plasma Electrolytic Oxidized Ti Alloy (Ti-6Al-4V) for Bio-implant Application. Metallurgical and Materials Transactions A 2016, 47, 788800, https://doi.org/10.1007/s11661-015-3256-y.

104. Aliofkhazraei, M.; Taheri, P.; SabourRouhaghdam, A.; Dehghanian, C. Study of nanocrystalline plasma electrolytic carbonitriding for CP-Ti. Materials Science 2007, 43, 791-799,https://doi.org/10.1007/s11003-0089024-z. 